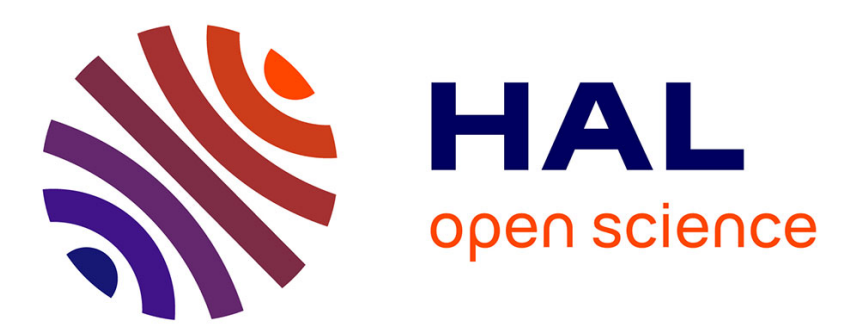

\title{
Tweaking Light-Emitting Diodes: A Multiobjective Optimal Design for New Luminaires
}

Jérémy Dulout, Bruno Jammes, Lionel Séguier, Angel Barroso, Pascal Dupuis, Georges Zissis, Corinne Alonso

\section{- To cite this version:}

Jérémy Dulout, Bruno Jammes, Lionel Séguier, Angel Barroso, Pascal Dupuis, et al.. Tweaking LightEmitting Diodes: A Multiobjective Optimal Design for New Luminaires. IEEE Industry Applications Magazine, 2018, 24 (4), pp.50-59. 10.1109/MIAS.2017.2740445 . hal-01575731

\section{HAL Id: hal-01575731 \\ https://hal.laas.fr/hal-01575731}

Submitted on 23 Aug 2017

HAL is a multi-disciplinary open access archive for the deposit and dissemination of scientific research documents, whether they are published or not. The documents may come from teaching and research institutions in France or abroad, or from public or private research centers.
L'archive ouverte pluridisciplinaire HAL, est destinée au dépôt et à la diffusion de documents scientifiques de niveau recherche, publiés ou non, émanant des établissements d'enseignement et de recherche français ou étrangers, des laboratoires publics ou privés. 


\title{
Multiobjective optimal design of Light Emitting Diode (LED) lightings
}

\author{
Jérémy Dulout ${ }^{1}$, Bruno Jammes ${ }^{1}$, Lionel Séguier ${ }^{1}$, Angel Barroso ${ }^{1,2}$, Pascal Dupuis ${ }^{2}$, \\ Georges Zissis ${ }^{2}$, Corinne Alonso ${ }^{1}$
}

${ }^{1}$ LAAS-CNRS, Université de Toulouse, CNRS, UPS, France

${ }^{2}$ LAPLACE, Université de Toulouse, CNRS, UPS, France

e-mail: \{jdulout, jammes, alonsoc\}@laas.fr georges.zissis@laplace.univ-tlse.fr

\begin{abstract}
In this paper, a Pareto multiobjective optimization is performed to design new luminaires, finding the optimal forward current, number of LEDs and proper heatsink by taking into account the cost, the energy consumption and the impact on the environment (life cycle analysis from cradle to grave). Three commercialized white LEDs have been studied and modelled in terms of optical, electrical, thermal and aging performances. The multiobjective methodology is also applied to other lamps (incandescent, halogen, fluorescent), indicating that LED lighting has a great potential of energy and cost savings with a minimization of environmental impacts on the long run.
\end{abstract}

Keywords - Lifetime estimation, Light emitting diodes (LED), Light sources, Life cycle analysis (LCA), multiobjective optimization, Pareto optimality.

\section{INTRODUCTION}

In a global context of rising concerns about climate change faced to a continuous increase of electricity demand [1], the use of LED solid-state lighting (SSL) with high electricity to light conversion efficiency is a promising solution. Indeed, the average efficiency of an LED is around $35 \%$, far better than incandescent light bulbs and fluorescent lamps (respectively 5\% and 20\%) [2]. In a report from the U.S. Department of Energy (DOE) [3], a 2030 scenario proposing a high LED market penetration has been studied. It would enable up to $60 \%$ of energy savings compared to a scenario without LED, which corresponds to $395 \mathrm{TWh}$ saved annually (equivalent to the annual electricity consumption of 36 million U.S. homes). Moreover, the overall environmental impact (resource consumption, pollution of soil, water and air...) of LED lamps is also better than the other commercialized lighting technologies. Main results are presented in studies dealing with life cycle assessment (LCA) [4]-[5].

LED-based SSL is fully controllable and could offer a lot of innovative and exclusive functionalities such as connected lighting applications, visible light communication (VLC)... To do so, this type of lighting is supplied by a power converter, also called LED driver. A LED driver usually works in continuous conduction mode (CCM) and regulates the current of the luminaire with a single current control loop [6] but other more complex control schemes using additional sensors enable to control accurately (spectral composition) and efficiently LED lamps [7]-[8]. The control is crucial to ensure LED good performances since current waveform has photometrical and colorimetrical impacts on light emission [9]. Last but not least, some additional practices have to be followed to control LED lamps in order to avoid any potential health issues inherited from LED flickering [10]-[12].

Despite the numerous benefits of LEDs (low energy consumption, very long lifetime, full controllability...), compared to other technologies the purchase price of LEDs is still a hurdle to the adoption of LED lighting.

In this paper, a special attention is paid to the operating conditions of LED. The level of forward current is crucial because it affects the LED junction temperature which defines the light output and the aging behaviors of the LED [13]-[14]. Recent studies have reported the relationships between photometric, electrical and thermal aspects for LED systems [14]-[16].

The purpose of this work is to find the best trade-off between three conflicting objectives: the environmental impact, the cost and the energy consumption of the luminaire. First, based on the main results of our previous study [17], a new LED model is proposed in this paper and experimentally validated on three types of white LEDs. Then, to solve this multiobjective optimization problem, a method based on Pareto optimality [18] is developed and enables the comparison of all lighting technologies.

This paper is organized as follows: section II introduces the optimization method to design a LED luminaire and also the specifications chosen to validate the approach. In section III, a luminous efficacy study on three different white LEDs is presented. Section IV details the thermal model of an LED. The aging model of an LED is described in section V. In section VI, the cost of an LED luminaire with heatsinks and the life cycle assessment are discussed. In section VII, results are presented and a comparison with other lighting devices is performed. A conclusion is given in section VIII. 


\section{OPTIMIZATION METHODOLOGY}

This work aims to design a $3600 \mathrm{~lm}$ LED luminaire corresponding to a standard lamp constituted by 3 fluorescent - $1200 \mathrm{~lm}$ tubes of $14 \mathrm{~W}$, which is supposed to operate 3744 hours per year (12 hours a day, 6 days per week and 52 weeks per year). The number of LEDs, the level of forward current and the choice of heatsink are the key parameters of the design.

As LEDs have not exactly the same V-I characteristics, their electrical association to create a luminaire can cause some photo-electro-thermal troubles. In the study [19], different LED associations (single string, series string or series-parallel string) are presented with a method to achieve current equalization. In [20], a series-parallel connection of LEDs is demonstrated as the topology that ensure the best performances (luminous efficacy and uniformity) of a LED luminaire.

Thus, in this study, the first parameter to optimize is the current supplied per LED. In an iterative and incremental way, the effect of different forward currents (from $0.1 \mathrm{~mA}$ up to $700 \mathrm{~mA}$ ) on different luminaire configurations will be simulated. The LED light output and electro-thermal behaviors are described in sections III and IV to propose a complete LED model depending on the forward current. Hence, as presented in Fig. 1, this methodology enables to calculate the annual cost, annual consumption and environmental impact of each luminaire configuration.

The Pareto method is used to find the best trade-off between the three objectives previously presented. The nonlinear multiobjective minimization problem between $k$ conflicting objectives and $n$ decision variables can be defined as follows:

$$
\begin{gathered}
\text { minimize }\left\{f_{1}(\boldsymbol{x}), \ldots, f_{k}(\boldsymbol{x})\right\} \\
\text { subject to } \boldsymbol{x} \in S
\end{gathered}
$$

where $f_{i}$ are the objective functions, $\boldsymbol{x}$ a decision vector belonging to a feasible set $S \subset \mathbb{R}^{n}$.

In multiobjective optimization, the optimal solution is not unique, a set of non-dominated solutions forms the so-called Pareto front [18], [21]. If we consider two solutions belonging to the Pareto set, one solution is better than the other on some objectives but also worse on at least one objective. Indeed, a solution $\boldsymbol{x}_{\boldsymbol{p}} \in S$ is said Pareto-optimal if there does not exist another solution $\boldsymbol{x} \in S$ such that $f_{i}(\boldsymbol{x}) \leq f_{i}\left(\boldsymbol{x}_{\boldsymbol{p}}\right)$ for all $i=1, \ldots, k$ and $f_{j}\left(\boldsymbol{x}_{\boldsymbol{p}}\right)<f_{j}(\boldsymbol{x})$ for at least one index $j$.

In order to help the decision maker to choose one optimal solution amongst others, an ideal point can be set for each Pareto front. The coordinates of this ideal point correspond to the global minimum of the Pareto front on each objective. After normalization of the objectives, the optimal point of the Pareto set is the nearest point to the ideal point, according to its Euclidean distance [21].

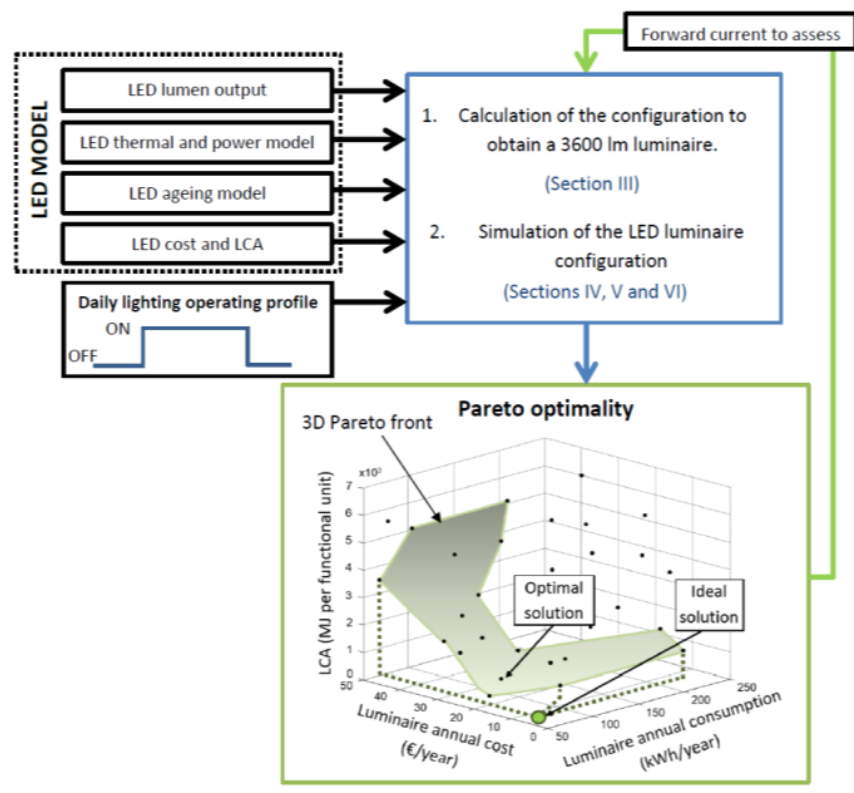

Fig. 1. Flowchart of the LED luminaire optimization methodology

In order to validate the different models described in the following sections, three different types of white LED with similar properties have been tested. Main characteristics given by manufacturers [22]-[24] are gathered in Table I.

TABLE I

\begin{tabular}{|c|c|c|c|}
\hline & $\begin{array}{l}\text { Cree } \\
\text { XTEAWT } \\
\text { GE5 }\end{array}$ & $\begin{array}{l}\text { Lumileds } \\
\text { LUXEON } \\
\text { Rebel plus } \\
\text { LX18- } \\
\text { P140-3 }\end{array}$ & $\begin{array}{l}\text { OSRAM } \\
\text { OSLON } \\
\text { square } \\
5 \mathrm{~L} 7 \mathrm{~N}-1\end{array}$ \\
\hline Viewing angle $\left(^{\circ}\right)$ & 115 & 120 & 120 \\
\hline $\begin{array}{l}\text { Luminous flux (lm) at } \\
85^{\circ} \mathrm{C} \text { junction temp. }\end{array}$ & $\begin{array}{l}130 \\
\text { @ } 350 \mathrm{~mA}\end{array}$ & $\begin{array}{l}103 \\
@ 350 \mathrm{~mA}\end{array}$ & $\begin{array}{l}194 \\
@ 700 \mathrm{~mA}\end{array}$ \\
\hline Forward voltage (V) & 3.4 & 2.85 & 2.85 \\
\hline Max. junction temp. $\left({ }^{\circ} \mathrm{C}\right)$ & 150 & 150 & 150 \\
\hline $\begin{array}{l}\text { Max. thermal resistance } \\
\text { junction/solder } \\
\left({ }^{\circ} \mathrm{C} / \mathrm{W}\right)\end{array}$ & 5 & 9 & 3.9 \\
\hline Purchase price $(€)$ & 1.36 & 1.36 & 2.38 \\
\hline
\end{tabular}

LEDS MAIN PERFORMANCES (MANUFACTURERS DATA) [22]-[24]

\section{LED LIGHT OUTPUT}

To determine the necessary number of LEDs to obtain the desired luminous flux, the luminous efficacy has been assessed with a sourcemeter Keithley 2602A, an integrating sphere and a spectrometer Specbos 1201 in a controlled temperature environment $\left(22^{\circ} \mathrm{C}\right)$. Experimental tests have been done with LEDs soldered on an insulated metal substrate printed circuit board (PCB). For each type of LEDs, three LEDs have been associated in series. All measures have been 
done after 40 minutes to ensure that LED junction temperature has been stabilized. This temperature is estimated based on the measurements of a thermocouple placed as close to the LED as possible. More details about thermal aspects will be given in section IV. Experimental results are shown in Fig 2.

Currents assessed in the Fig. 2 are $[0.1 ; 1 ; 5 ; 10 ; 20 ; 30 ; 50$; $70 ; 100 ; 150 ; 200 ; 250 ; 300 ; 400 ; 500 ; 600 ; 700] \mathrm{mA}$. Due to possible high junction temperatures that could cause irreversible damage, currents above $700 \mathrm{~mA}$ have not been tested. It can be noted that the forward current has a strong impact on the luminous efficacy, currents from $5 \mathrm{~mA}$ to $100 \mathrm{~mA}$ lead to the best luminous efficacy.

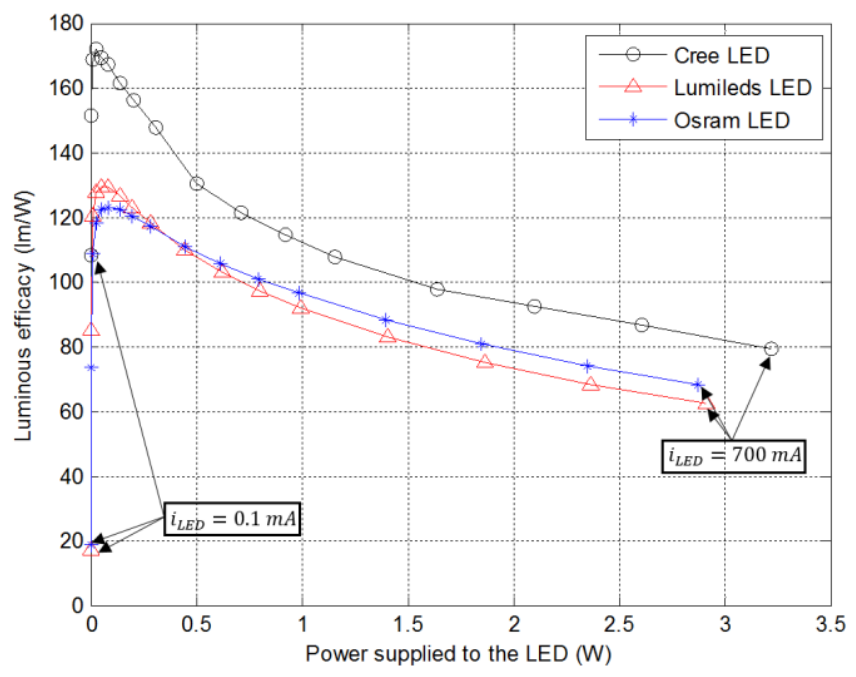

Fig. 2. Luminous efficacy vs. Power for the three tested LEDs

For each forward current, the number of LEDs, noted $\mathrm{N}_{L E D}$, required to achieve a $3600 \mathrm{~lm}$ luminous flux, can be calculated as follows:

$$
\mathrm{N}_{L E D}=\frac{\mathrm{F}_{d}}{\mathrm{~F}_{L E D}}=\frac{\mathrm{F}_{d}}{\varepsilon_{L E D}\left(\mathrm{P}_{L E D}\right) \times \mathrm{P}_{L E D}}
$$

where $\mathrm{F}_{d}$ and $\mathrm{F}_{L E D}$ are respectively the desired luminous flux of the luminaire and the luminous flux of a LED, $\varepsilon_{L E D}\left(\mathrm{P}_{L E D}\right)$ is the luminous efficacy of an LED for a given electrical power noted $\mathrm{P}_{L E D}$.

In the context of low consumption electric appliances, the consumption of the luminaire has to be taken into account. The different configurations are plotted in Fig. 3. The configuration corresponding to a supply current of $0.1 \mathrm{~mA}$ per LED is not presented because hundreds of thousands of LEDs are necessary to obtain a luminous flux of $3600 \mathrm{~lm}$.

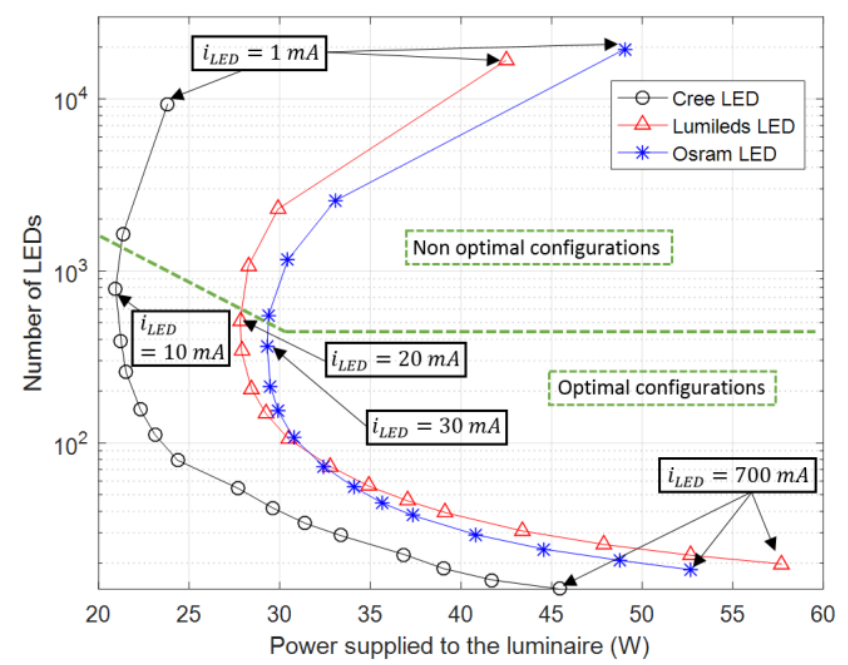

Fig. 3. Number of LEDs vs. power supplied to the luminaire

In the Fig. 3, the Pareto set is from $10 \mathrm{~mA}$ to $700 \mathrm{~mA}$ for Cree LED, from $20 \mathrm{~mA}$ to $700 \mathrm{~mA}$ for Lumileds LED, and from $30 \mathrm{~mA}$ to $700 \mathrm{~mA}$ for Osram LED. Indeed, the very low forward currents are not optimal because the energy consumption and the number of LEDs are both higher than other configurations. Moreover, a minimum value of forward current can be set to avoid a too high number of LEDs (for example greater than 250 LEDs per luminaire). In this case, according to our experiments, only currents higher than $50 \mathrm{~mA}$ will be considered.

The light output analysis enables to find the configurations that minimize both the number of LEDs and the energy consumption. Indeed, currents from $50 \mathrm{~mA}$ to $700 \mathrm{~mA}$ lead to possible optimal configurations. The next section is focused on the influence of the forward current on the junction temperature of the LED. In point of fact, the junction temperature affects the luminous flux and lifetime of an LED [13]-[16].

\section{THERMAL MODELING OF AN LED}

As any P-N junction, the junction temperature of an LED is increasing when supplied. Many models are available to accurately represent the thermal behavior of an LED such as the Shockley equation [25]-[26]. In this paper, a simplified steady state thermal model is derived from [15]. The different elements of the model are represented in Fig. 4-A and Fig 4-B. An LED luminaire can be modeled with a simple resistor network to define a static thermal model as illustrated in Fig. 4-C.

The junction temperature is difficult to measure and can be estimated by using a thermocouple placed as close as possible to the LED. The temperature measured by this thermocouple is called the solder point temperature. 

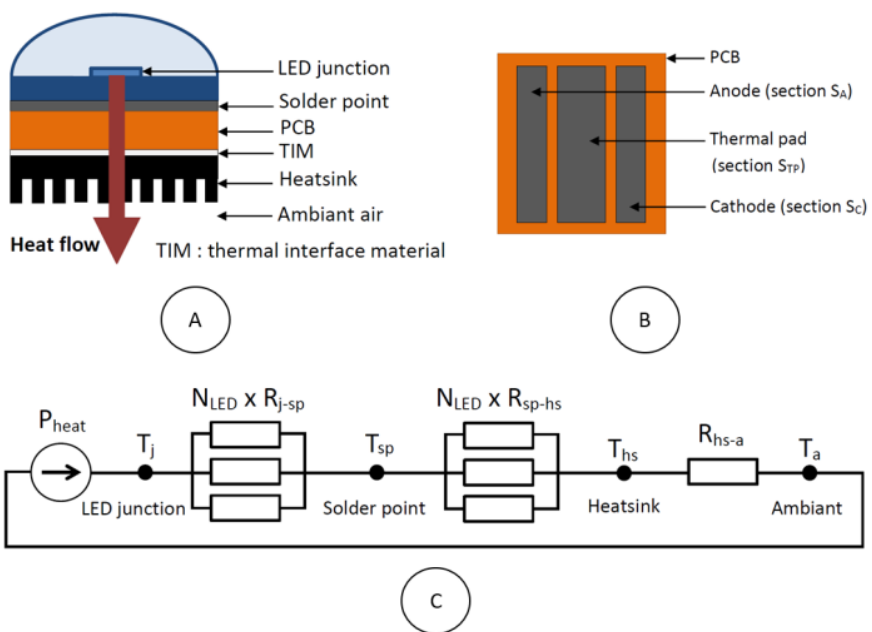

Fig. 4. A- Simplified scheme of an LED system, B- PCB footprint of an LED, C- Thermal model of an LED luminaire

Based on the static thermal model presented in Fig. 4-C, the temperature of the solder point can be predicted for each forward current. Thus, if $\mathrm{N}_{L E D}$ LEDs are mounted on the same heatsink, the temperature of the solder point can be computed with the following relation derived from Fourier's law of heat conduction:

$$
\mathrm{T}_{s p}=\mathrm{T}_{a}+\left(\frac{1}{\mathrm{~N}_{L E D}} \mathrm{R}_{s p-h s}+\mathrm{R}_{h s-a}\right) \mathrm{P}_{\text {heat }}
$$

where

$\mathrm{T}_{s p}$ and $\mathrm{T}_{a}$ are respectively the solder point and the ambient temperature $\left({ }^{\circ} \mathrm{C}\right)$

$\mathrm{N}_{L E D}$ is the number of LEDs mounted on the same heatsink.

$\mathrm{R}_{s p-h s}$ and $\mathrm{R}_{h s-a}$ are respectively the thermal resistance between solder point and heatsink and the thermal resistance between heatsink and ambient $\left({ }^{\circ} \mathrm{C} / \mathrm{W}\right)$

$\mathrm{P}_{\text {heat }}$ is the amount of input power converted by the LED as heat $(\mathrm{W})$

$\mathrm{P}_{\text {heat }}$ is calculated as follows:

$$
\mathrm{P}_{\text {heat }}=\eta_{\text {heat }} \mathrm{N}_{L E D} \mathrm{~V}_{f} \mathrm{I}_{f}
$$

where

$\eta_{\text {heat }}$ is the power losses coefficient of an LED. As explained in [27], an average value of 0.85 can be considered

$\mathrm{V}_{f}$ and $\mathrm{I}_{f}$ are respectively the forward voltage $(\mathrm{V})$ and the forward current (A) of a single LED.

The thermal resistance $\mathrm{R}_{s p-h s}$ corresponds to the sum of PCB and thermal grease thermal resistances. These thermal resistances have to be calculated based on their thermal conductivity and their contact area to the LED device.
Usually, a thermal resistance $\mathrm{R}_{x}$ is defined as follows:

$$
\mathrm{R}_{x}=\frac{\mathrm{L}}{k A}
$$

where

L is the thickness of the material $x(\mathrm{~mm})$

$\mathrm{k}$ is the conductivity of the material $x(\mathrm{~W} / \mathrm{mK})$

$\mathrm{A}$ is the contact area between the heating device and the material $x$, grey areas depicted in Fig. $4-\mathrm{C}\left(\mathrm{mm}^{2}\right)$

In order to evaluate the thermal behavior of LED devices, a very accurate power supply (battery cycler BioLogic BCS815) and a temperature chamber ESPEC SU-221 have been used. As previously mentioned, three strings of three different LEDs are assessed. A heatsink with a thermal resistance of $1.2 \mathrm{~K} / \mathrm{W}$ has been selected and a silicone thermal grease with a conductivity of $0.9 \mathrm{~W} / \mathrm{mK}$ has been used to increase the thermal conduction between the PCB and the heatsink. LED strings have been powered separately in a controlled environment of $25^{\circ} \mathrm{C}$ with 30 minutes current pulses from $50 \mathrm{~mA}$ to $700 \mathrm{~mA}$ by $50 \mathrm{~mA}$. Rests of 30 minutes have been done between two pulses. A very low dispersion between LEDs from the same manufacturer is to notice. In Fig. 5, the voltage across each LED is illustrated.

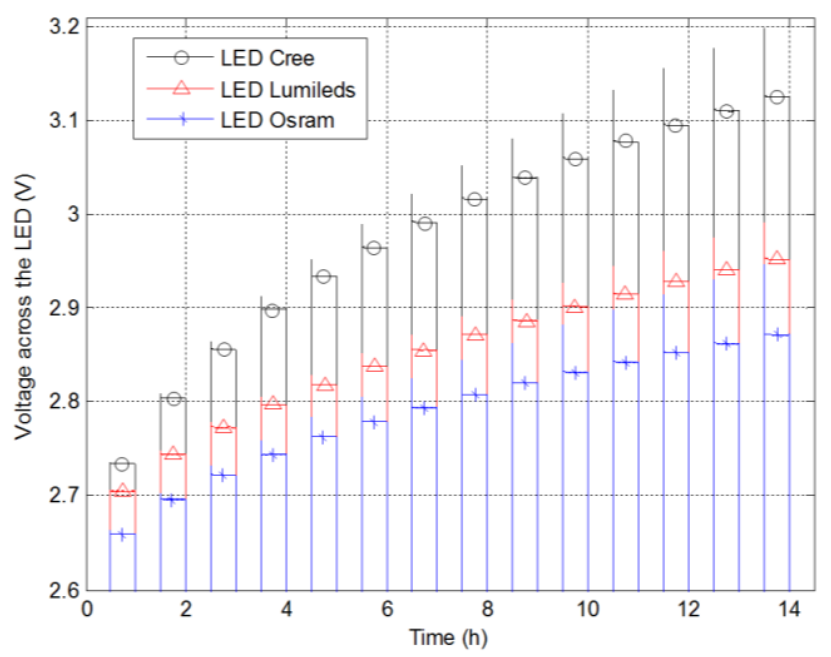

Fig. 5. Voltage across each LED for different forward currents

With the previous voltage measurements and a good estimation of $\mathrm{R}_{s p-h s}$, it is possible to predict the temperature at the solder point by using equation (3). It is to notice that a small drop of voltage occurs across a heating LED, phenomenon which can be neglected if the LED junction temperature is lower than $80^{\circ} \mathrm{C}$.

The experimental and modelled evolutions of the solder point temperature are illustrated in Fig. 6. Only one temperature has been plotted for Cree and Lumileds LEDs because they have exactly the same temperature during the experiments. The temperature of the Osram LED is very low compared to the other ones. To have a model which well fits with data, an abnormal very low $\eta_{\text {heat }}$ has been computed $\left(\eta_{\text {heat }}=0.45\right)$. 


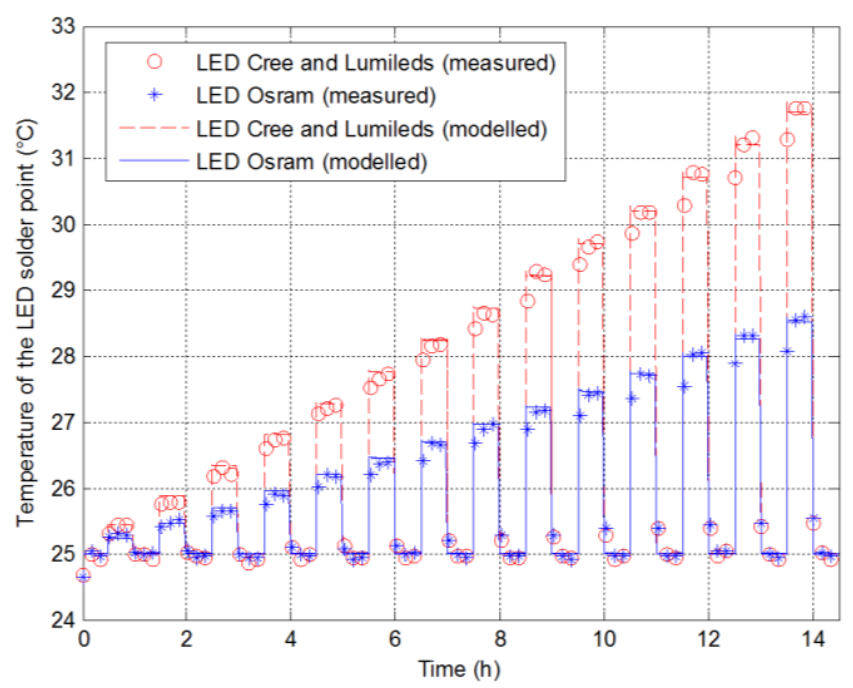

Fig. 6. Evolution of LED solder point temperatures

To evaluate the junction temperature of the LED, the relation between the junction temperature and the solder point of an LED is defined as:

$$
\mathrm{T}_{j}=\mathrm{T}_{s p}+\frac{1}{\mathrm{~N}_{L E D}} \mathrm{R}_{j-s p} \mathrm{P}_{h e a t}
$$

where

$\mathrm{T}_{j}$ is the junction temperature of the $\operatorname{LED}\left({ }^{\circ} \mathrm{C}\right)$

$\mathrm{R}_{j-s p}$ is the thermal resistance of the LED between junction and solder point $\left({ }^{\circ} \mathrm{C} / \mathrm{W}\right)$

According to Fig. 3, the luminaire needs to be powered between $20 \mathrm{~W}$ and $60 \mathrm{~W}$ so large heatsinks with a thermal resistance of $0.4 \mathrm{~K} / \mathrm{W}, 1.2 \mathrm{~K} / \mathrm{W}$ and $2 \mathrm{~K} / \mathrm{W}$ have been selected to dissipate the generated heat. In the Fig. 7, the junction temperature has been estimated for the different heatsinks.

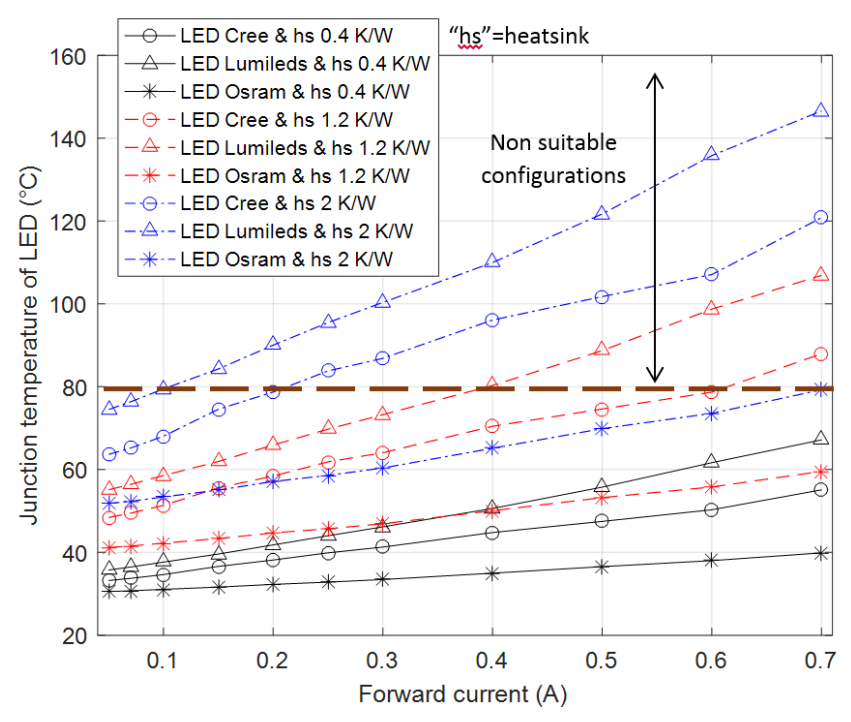

Fig. 7. Junction temperature estimation for different heatsinks
The thermal management of LED is crucial. According to our experiments the drop of luminous flux due to the rise of temperature, can be limited to $10 \%$ if the junction temperature remains below $80^{\circ} \mathrm{C}$. In this case, the drop of luminous flux can be neglected because it is not visible for the common human eye [28]. In Fig. 7, it can be noticed that several configurations with the $2 \mathrm{~K} / \mathrm{W}$ and the $1.2 \mathrm{~K} / \mathrm{W}$ heatsinks have to be removed because the junction temperature is too high.

The next section presents how to estimate the aging of a LED according to its junction temperature.

\section{LED AGING MODEL}

The study of LED aging, also called lumen maintenance, is determined by its lumen depreciation. The lifetime of an LED is defined by the number of operating hours before the luminous flux decreases below $70 \%$ of its initial value. This lifetime is often noted L70. According to the Illuminating Engineering Society of North America (IESNA), the standard TM 21 provides a method to assess the lumen maintenance of LEDs.

A simplified model of lifetime has been computed based on [28] as illustrated in Fig 8. In this model, it is assumed that the aging of the LED is related to the junction temperature and the forward current. The lifetime is shorter for warmer junction temperatures. As it is a simplified model, it will be considered that currents below $350 \mathrm{~mA}$ have the " $350 \mathrm{~mA}$ behavior", whereas higher currents will follow the "700 mA aging model".

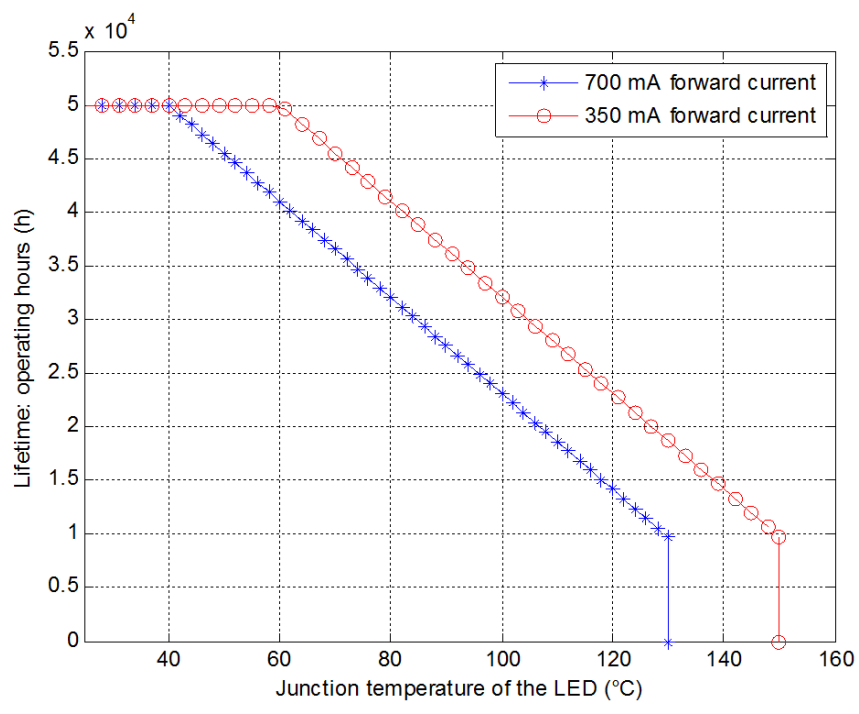

Fig. 8. Simplified lifetime model of an LED [28]

The number of years of LED operation can be estimated for different junction temperatures and forward currents:

$$
\mathrm{n}_{\text {life }}=\frac{\text { Lifetime }\left(\mathrm{T}_{j L E D}, \mathrm{I}_{\mathrm{f}}\right)}{T_{\text {op_year }}}
$$


where

Lifetime $\left(\mathrm{T}_{j L E D}, \mathrm{I}_{\mathrm{f}}\right)$ is the maximum number of operating hours for a given junction temperature and forward current, as described in Fig. 8.

$T_{\text {op_year }}$ is the number of operating hours per year.

Now that luminous, thermal and aging behavior of LED have been discussed, the cost model and life cycle analysis of the luminaire needs to be developed.

\section{LED LUMINAIRE COST ANALYSIS AND LIFE CYCLE ASSESSMENT}

In this study, the consumption and the cost of the luminaire are separately determined, so no assumption has to be done on the price of electricity, which is arbitrary and varies from a state to another, depends on the season...

As this method compares different LED luminaire configurations which roughly need the same supplied power, the cost of LED drivers is assumed to be identical, and consequently will not be considered in this analysis. No cost of maintenance is needed, the LED luminaire will be replaced according to the L70 lifetime. The annual cost ( $€ /$ year) of the luminaire can be defined as in [29]:

$$
C_{\text {year_lighting }}=C_{\text {purchase }} \times C R F
$$

$C_{\text {purchase }}(€)$ is the initial capital cost (purchase price) of the luminaire corresponding to the cost of LEDs and heatsink:

$$
C_{\text {purchase }}=\mathrm{N}_{L E D} \times\left(C_{L E D}+C_{\text {Heatsink }}\right)
$$

where

$C_{L E D}$ is the price $(€)$ of a single LED (cf. table I),

$C_{\text {Heatsink }}$ is the additional cost per LED of $0.6 €, 0.35 €$ and $0.2 €$ respectively corresponding to $0.4 \mathrm{~K} / \mathrm{W}$, $1.2 \mathrm{~K} / \mathrm{W}$ and $2 \mathrm{~K} / \mathrm{W}$ heatsinks.

$C R F$ is the capital recovery factor. It enables the calculation of the equivalent uniform annual worth over the lifetime of the luminaire ( $\mathrm{n}_{\text {life }}$ in years) with a given initial capital cost and an interest rate $\mathrm{i}$ (5\% have been considered in this study). It is defined as in [29]-[30]:

$$
C R F=\frac{i(1+i)^{\mathrm{n}_{\text {life }}}}{(1+i)^{\mathrm{n}_{\text {life }}}-1}
$$

The annual energy consumption of the lamp is:

$$
E_{\text {year_lighting }}=T_{\text {op_year }} \mathrm{P}_{\text {Lum }}
$$

As illustrated in Fig. 9, one Pareto front per type of LED is obtained (solid line). For Cree and Osram components, each heatsink leads to an optimal configuration for a given range of power. When the power supplied to the luminaire increases, more expensive and high dissipative heatsinks are optimal. For Lumileds LEDs, the lowest dissipative heatsink does not lead to an optimal configuration because of its high junction to solder point thermal resistance.
All the configurations leading to a junction temperature higher than $80^{\circ} \mathrm{C}$ have been removed from the Fig. 9 .

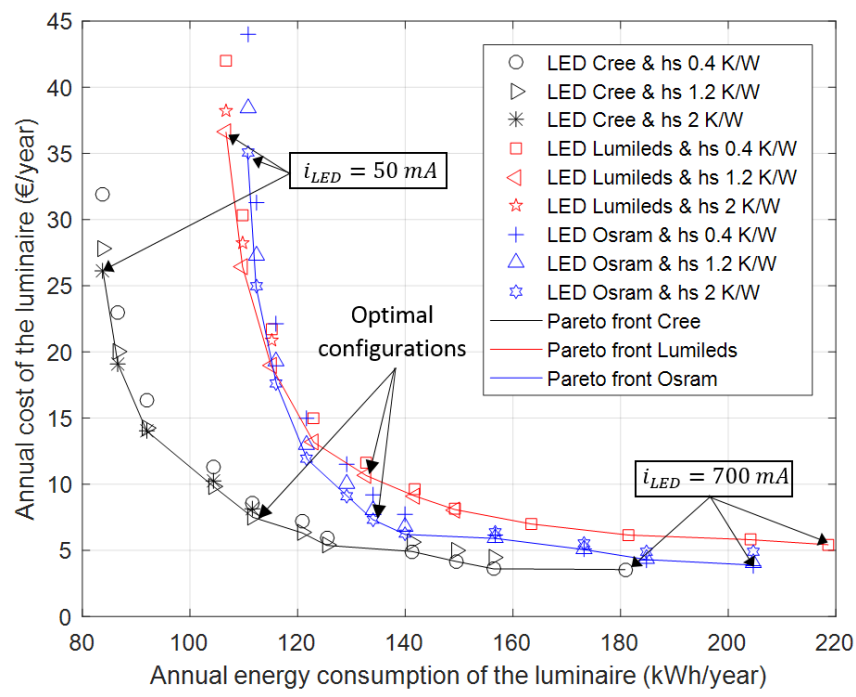

Fig. 9. Annual cost vs. energy consumption of the LED luminaire

For each type of LED, the optimal configuration depicted in Fig. 9 is the solution that minimizes its distance to the ideal point, as illustrated in Fig. 1 and explained in [21]

To conclude this section, the optimal configurations are 42 Cree LEDs at $200 \mathrm{~mA}, 57$ Lumileds at $200 \mathrm{~mA}$, and 45 Osram LEDs at $250 \mathrm{~mA}$. A $2 \mathrm{~K} / \mathrm{W}$ heatsink is sufficient for Osram devices whereas a $1.2 \mathrm{~K} / \mathrm{W}$ is needed for Cree and Lumileds.

The last objective to minimize is the life cycle assessment (LCA) which is often used to quantify the environmental impact of industrial devices. In order to fairly compare lighting devices, a functional unit has to be set. The most relevant one is quantity of luminous flux for a given time, expressed in Mlm.hrs [4]-[5] and [31]. In this paper, the functional unit is the annual lighting service of a $3600 \mathrm{~lm}$ luminaire that is assumed to operate 3744 hours per year so the functional unit is close to $13.5 \mathrm{Mlm}$.hrs. The results of the LCA are given in terms of primary energy consumption and expressed in $\mathrm{MJ}$ per functional unit.

Four main life stages are studied to calculate the energy consumed over the entire life of the product, as listed below:

- Manufacturing stage: due to many confidential industrial processes, the calculation of this stage LCA is uncertain and includes numerous assumptions. Following the method given in [5] for LED lamps, it appears that this stage can represents a large part of the total LCA, as described in Fig. 10

- Transportation stage: this stage can be neglected in this study because it represents less than one percent of the total LCA [5].

- Use stage: As explained in [4]-[5] and [31], the environmental impact of any type of lamp is by far mainly due to the energy consumed for using the luminaire. The lumen output depreciation of LED devices, non-linear phenomenon 
[32], has not been considered in this calculation. The energy consumption (in MJ per functional unit) of the use stage is given by the following equation [5]:

$$
E_{L C A}=\frac{3.6}{1000} \times \mathrm{P}_{L E D} \times \text { Lifetime }\left(\mathrm{T}_{j L E D}, \mathrm{I}_{\mathrm{f}}\right) \times C_{m i x} \times N_{\text {equ }}
$$

where

$C_{m i x}$ is the secondary to primary energy conversion factor based on the electricity production mix. In this study, $C_{\text {mix }}=2.45$ corresponding to the EU 2010 electricity production [5]. This factor is very important to know the real environmental impact of the use stage.

$N_{\text {equ }}$ is the number of equivalent LEDs satisfying both luminous flux and lifetime requirements to obtain the desired luminaire.

$$
N_{e q u}=\frac{\mathrm{F}_{d} \times t_{d}}{\mathrm{~F}_{L E D} \times \text { Lifetime }\left(\mathrm{T}_{j L E D}, \mathrm{I}_{\mathrm{f}}\right)}
$$

where $t_{d}$ is the desired number of lighting hours. In this paper, $t_{d}=T_{\text {op_year }}$ because the LCA is assessed for one year of service.

According to relations (2) and (12), a linear relation between the energy of the use stage LCA and the annual consumption of the luminaire can be written.

$$
E_{L C A}=\frac{3.6}{1000} \times C_{m i x} \times t_{d} \times \mathrm{P}_{L u m}
$$

When less than hundred LEDs are needed to make a luminaire, the use stage LCA is by far the main consuming stage of LED life, as shown in Fig. 10.

- End-of-life stage: the waste management is a major issue, especially when toxic materials are at stake. Three scenarios have been assessed in [4]: complete recycling, disposal in a landfill and disposal in an incinerator. It appears that the energy consumed during the end-of-life stage represents up to $3 \%$ of the entire LCA and the difference between the three scenarios accounts for less than $1 \%$. It can be noticed that recycling is more efficient [4], [31].

Due to their low impact on the final results, the transportation and end-of-life stages have been neglected.

The results of the LCA study are represented in Fig. 10. The minimum primary energy consumption is obtained for a current per LED around $200 \mathrm{~mA}$. By taking into account the manufacturing stage, the energy consumption of the configurations that need a large number of LEDs increases significantly. The results given in Fig. 10 are similar to the predictions presented in [5] about LED technology from 2015. It is to notice that LCA for LED devices is quite difficult to manage because of the fast development of this technology in comparison with conventional lamps. It implies changes in manufacturing processes and rising performances (luminous efficacy, CRI) which strongly affect the final LCA results.

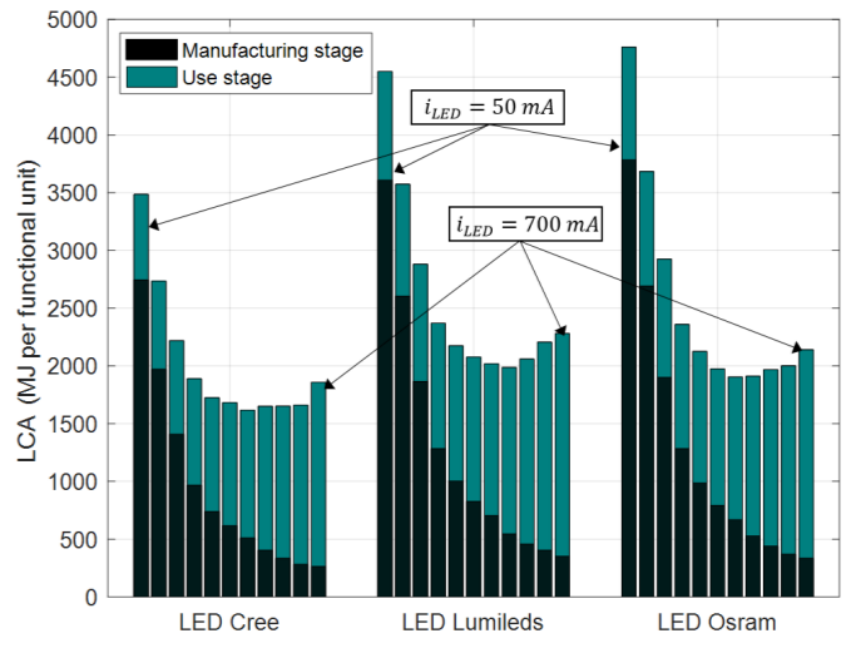

Fig. 10. Manufacturing and use stages LCA for different LED configurations

In Fig. 11, the three Pareto fronts have been represented. For each forward current value, the different heatsinks do not influence neither the energy consumption of the luminaire (assuming that the power does not change when the junction temperature increases until $80^{\circ} \mathrm{C}$ ) nor the different LCA (it has been assumed that the LCA is the same for the three heatsinks). In this case, for each LED, the Pareto front is not a surface but a line. Thus, the non-dominated solutions are the one previously described in Fig. 9. When LCA is taken into account (especially the manufacturing stage), the configurations involving a high number of LEDs and a low annual energy consumption are very far from the ideal point.

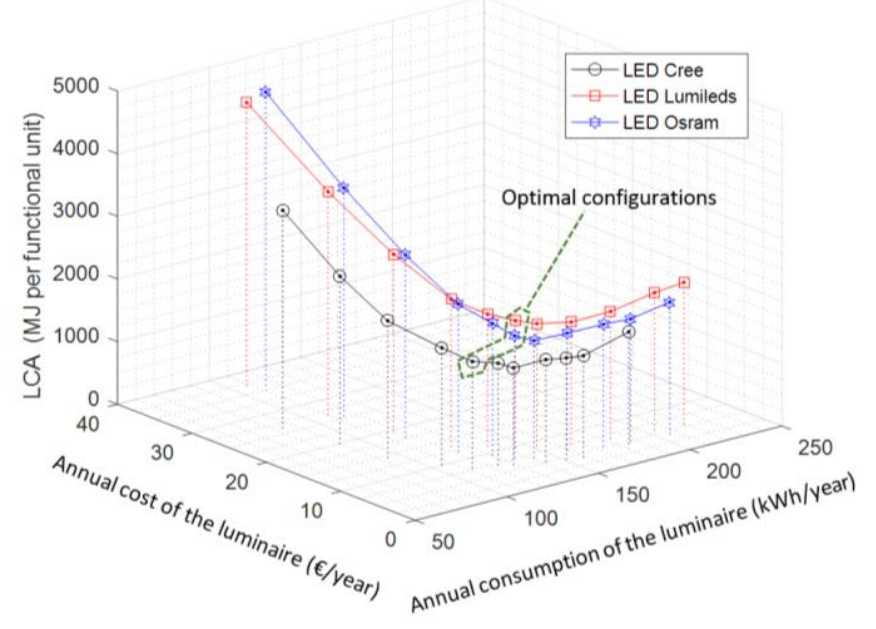

Fig. 11. Optimization of three objectives

According to Fig. 11, the optimal configurations for Cree and Osram LEDs are those presented in Fig. 9. But for Lumileds LEDs, taking LCA into account shifts the optimal configuration to a higher forward current $(250 \mathrm{~mA}$ instead of $200 \mathrm{~mA}$ ) and a lower number of LEDs (47 instead of 57). 
The LED optimal configurations have been found subject to the annual cost, annual energy consumption and LCA (cf. Fig. 11). A comparative study with conventional lighting (halogen lamp, incandescent lamp and compact fluorescent lamp) will be carried out in the next section.

\section{COMPARISON WITH CONVENTIONAL LAMP TECHNOLOGIES}

In table II are gathered data from a report of the U.S. DOE [32] corresponding to A19 light bulbs of conventional lighting.

\section{TABLE II}

MAIN CHARACTERISTICS OF DIFFERENT COMMERCIALIZED LAMPS

\begin{tabular}{c|c|c|c}
\hline & Halogen & Incandescent & CFL \\
\hline $\begin{array}{c}\text { Luminous efficacy } \\
(\mathrm{lm} / \mathrm{W})\end{array}$ & 20 & 15 & 70 \\
\hline $\begin{array}{c}\text { Operational lifetime } \\
(\mathrm{h})\end{array}$ & 8400 & 1000 & 12000 \\
\hline Price (€/klm) & $2.33^{*}$ & $0.59^{*}$ & $1.86^{*}$ \\
\hline
\end{tabular}

* Conversion EURO/Dollar: $1 \$=0.93 €$

As in the previous section, no ballast cost will be considered, assuming that the different ballasts and LED drivers have the same price. In Fig. 12, the optimal configurations obtained in the previous section are compared to the commercialized lamps described in table II. It is to remind that the results are given for a luminaire operating 3744 hours per year (12 hours a day, 312 days per year).

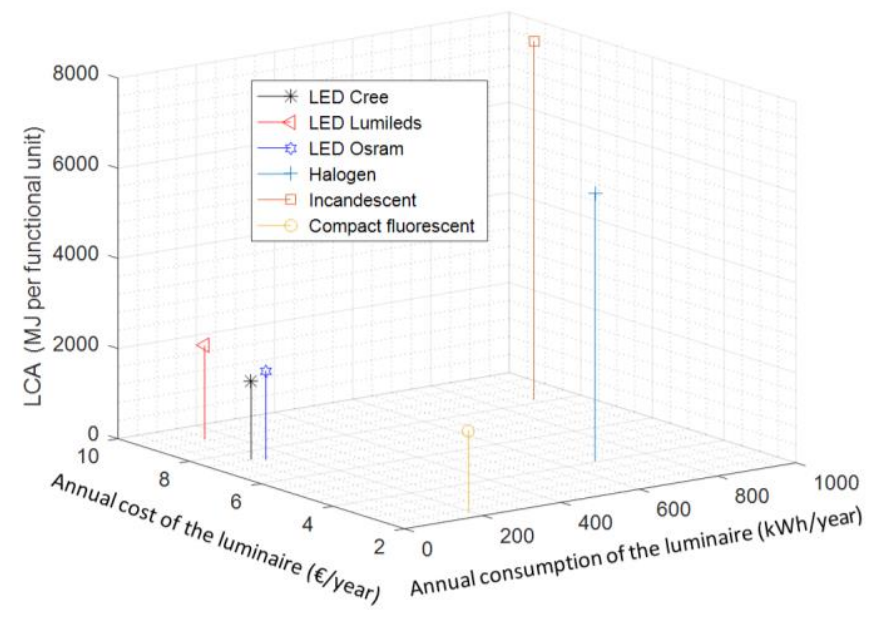

Fig. 12. Comparison all lighting technologies

Due to a high luminous efficacy, LED lamps and CFL have both a low annual energy consumption and low energy needs on their entire life (LCA). CFL is today the cheapest device but if we consider a cost of $0.1 €$ per $\mathrm{kWh}$, the energy consumption gap between LED and CFL is sufficient to make LED lamps the cheapest lighting technology (considering both purchase and energy consumption costs). The same remark can be done on halogen lamps which are nearly three times less expensive than LED lamps but consume more than three times more. Incandescent lamps are by far less effective than any other lighting technology.

In order to go further, the models of LED driver failure and optical components degradation, which may reduce the L70 lifetime [32], have to be introduced to fairly compare all lighting technologies. Moreover, assessments of the LED lumen depreciation in standardized operating conditions should also be analyzed more deeply to describe LEDs under real-life conditions.

\section{CONCLUSION}

A new methodology has been proposed to find the optimal design of a luminaire. The forward current, number of LEDs and heatsink have been selected in order to minimize the cost of purchase, the energy consumption and the ecological footprint. This method takes into account the luminous output, the thermal management, the lifetime prediction, the cost of purchase and the life cycle assessment (LCA). For the three selected LEDs, it appears that optimal forward currents are between $200 \mathrm{~mA}$ and $250 \mathrm{~mA}$. The use of LCA enables to point out the significant energy consumption related to the manufacturing stage. A comparison with other lighting technologies shows that LED lightings have better performances than CFL, halogen and incandescent lamps in terms of energy consumption and LCA. The overall cost based on purchase price and cost of annual energy consumption is also optimal for LED devices.

Due to the modularity of this methodology, LED models used in this paper can be improved or adapted to any type of lamp. Other models may be added to improve the relevance of this analysis: reliability of the LED configuration (string, series string, series-parallel string modules), failure distribution of LED drivers, LED lumen depreciation...

\section{ACKNOWLEDGMENT}

This work was partially supported by the NeOCampus project from the Université de Toulouse, Toulouse III Paul Sabatier, France.

\section{REFERENCES}

[1] International Energy Agency (IEA), Key World Energy STATISTICS 2015, Paris 2015.

[2] Colin J. Humphreys, Solid-State Lighting, MRS Bulletin, Volume 33, Issue 04, avril 2008, pp 459-470.

[3] DOE SSL Program, "Energy Savings Forecast of Solid-State Lighting in General Illumination Applications," August 2014. [Online]. [Accessed February 2017] Available: http://apps1.eere.energy.gov/buildings/publications/pdfs/ssl/ener gysavingsforecast14.pdf

[4] Paolo Principi, Roberto Fioretti, "A comparative life cycle assessment of luminaires for general lighting for the office compact fluorescent (CFL) vs Light Emitting Diode (LED) - a case study", Journal of Cleaner Production 83 (2014) 96-107. 
[5] DOE SSL Program, "Life-Cycle Assessment of Energy and Environmental Impacts of LED Lighting Products - Part I: Review of the Life-Cycle Energy Consumption of Incandescent, Compact Fluorescent, and LED Lamps", technical report, february 2012 updated august 2012.

[6] Ray-Lee Lin, Jhong-Yan Tsai, Shun-Yao Liu, Hsin-Wei Chiang, "Optimal Design of LED Array Combinations for CCM SingleLoop Control LED Drivers", IEEE Journal of Emerging and Selected Topics in Power Electronics, Vol. 3, No. 3, September 2015, pp. 609-616.

[7] M. Nishikawa, Y. Ishizuka, H. Matsuo, and K. Shigematsu, "An LED drive circuit with constant-output-current control and constant-luminance control," in Proc. Telecommun. Energy Conf. (INTELEC 2006), Sep., pp. 1-6.

[8] B. Ackermann, V. Schulz, C. Martiny, A. Hilgers, and X. Zhu, "Control of LEDs," in Proc. IEEE IAS 2006, Oct., pp. 26082615.

[9] Pedro S. Almeida, Fernando J. Nogueira, Luiz F. A. Guedes, Henrique A. C. Braga, "An experimental study on the photometrical impacts of several current waveforms on power white leds", XI Brazilian Power Electronics Conference, pp. 728 - 733, 11-15 Sept. 2011.

[10] Arnold Wilkins, Jennifer Veitch, Brad Lehman, "LED Lighting Flicker and Potential Health Concerns: IEEE Standard PAR1789 Update", IEEE Energy Conversion Congress and Exposition, 12-16 Sept. 2010, pp. $171-178$.

[11] IEEE standard 1789-2015, "IEEE Recommended Practices for Modulating Current in High-Brightness LEDs for Mitigating Health Risks to Viewers".

[12] Christophe Martinsons, Georges Zissis, "Potential Health Issues of Solid-State Lighting", IEA 4E final report, 24 September 2014.

[13] L. Trevisanello, M. Meneghini, G. Mura, M. Vanzi, M. Pavesi, G. Meneghesso, and E. Zanoni, "Accelerated Life Test of High Brightness Light Emitting Diodes”, IEEE Trans. Device Mater. Rel., vol. 8, no. 2, pp. 304-311, Jun. 2008.

[14] Thermal Management Considerations for SuperFlux LEDs, application brief AB20-4, LUMILEDS.

[15] S. Y. (Ron) Hui, Y. X. Qin, "A general Photo-Electro-Thermal Theory for Light Emitting Diode (LED) systems", IEEE Transactions on Power Electronics, vol. 24, no. 8, pp. 19671976, august 2009.

[16] S. Buso, G. Spiazzi, M. Meneghini, and G. Meneghesso, "Performance Degradation of High-Brightness Light Emitting Diodes under DC and pulsed bias", IEEE Trans. Device Mater. Rel., vol. 8, no. 2, pp. 312-322, June 2008.

[17] Jérémy Dulout, Angel Barroso, Lionel Séguier, Bruno Jammes, Pascal Dupuis, Georges Zissis, Corinne Alonso. "Multiobjective methodology to find the optimal forward current to supply light emitting diode (LED) lightings", IEEE Industry Applications Society Annual Meeting, 2-6 Oct. 2016.

[18] Ning Xiong, Daniel Molina, Miguel Leon Ortiz \& Francisco Herrera, "A walk into Metaheuristics for Engineering Optimization: Principles, Methods and Recent Trends", international journal of computational intelligence systems, vol. 8 issue 4, pages 606-636, July 2015.
[19] Pedro S. Almeida, Joao M. Jorge, Claudio R.B.S. Rodrigues, Guilherme M. Soares, "A Novel Method of Current Equalization in LED Strings Based on Simple Linear Circuit", IEEE International Symposium on Industrial Electronics, June 2011, pp. $95-100$.

[20] A.Barroso, P.Dupuis, C.Alonso, G.Zissis, "Impact of current sharing issue on luminance and uniformity", Proc. 15th International Symposium on the Science and Technology of Lighting Systems, pp 335-340, June 2016, Kyoto (Japan).

[21] Jesús A. De Loera, Raymond Hemmecke, Matthias Köppe, "Pareto Optima of Multicriteria Integer Linear Programs", Informs Journal on Computing vol. 21 issue 1, p. 39-48, 2008.

[22] Datasheet, Cree XLamp XT-E LEDs, CLD-DS41 rev 14 [Online]. [Accessed February 2017] Available: http://www.cree.com/ /media/Files/Cree/LED-Componentsand-Modules/XLamp/Data-and-Binning/XLampXTE.pdf

[23] Datasheet, DS107 LUXEON Rebel PLUS Product Datasheet 2015 [Online]. [Accessed February 2017] Available: http://www.lumileds.com/uploads/380/DS107-pdf

[24] Datasheet, OSLON Square Datasheet Version $1.2 \mathrm{GW}$ CSSRM1.CC [Online]. [Accessed February 2017] Available: http://www.osramos.com/Graphics/XPic4/00199140_0.pdf/GW\%20CSSRM1.CC $\% 20 \% 200$ SLON\%20 Square\%20(EnglishDeutsch).pdf

[25] E. Fred Schubert, Light-Emitting Diodes, second edition, Cambridge University Press, july 2006, pp.59-112.

[26] Andras Poppe, "Multi-domain compact modeling of LEDs: An overview of models and experimental data", Microelectronics Journal, Volume 46 Issue 12, December 2015, pp. 1138-1151.

[27] Yaxiao Qin, Deyan Lin, S. Y. (Ron) Hui, "A simple method for comparative study on the thermal performance of leds and fluorescent lamps", IEEE Transactions on Power Electronics, vol. 24, no. 7, pp. 1811-1818, July 2009.

[28] U.S. Department of Energy, "LED Measurement Series: LED Luminaire Reliability”, PNNL-SA-61137, October 2009.

[29] Leland Blank, Anthony Tarquin, "Engineering economy seventh edition", McGraw-Hill, 2012.

[30] Donald S. Remer, Armando P. Nieto, "A compendium and comparison of 25 project evaluation techniques. Part I: Net present value and rate of return method", Int J. Production Economics 42 (1995), 79-96.

[31] Leena Tähkämö, Marjukka Puolakka, Liisa Halonen, Georges Zissis, "Comparison of Life Cycle Assessments of LED Light sources", Journal of Light \& Visual Environment, vol. 36 (2012) no. 2, p. 44-54.

[32] DOE SSL Program, "Solid-State Lighting R\&D plan", June 2016, [Online]. [Accessed February 2017] Available: https://energy.gov/sites/prod/files/2016/06/f32/ssl_rdplan_\%20jun2016_2.pdf 